\title{
PROJETO O TEMPO E O CENTRO: O EDUCANDO COMO INVESTIGADOR CRÍTICO NOS ROTEIROS HISTÓRICOS - CULTURAIS
}

\author{
Eduardo Pacheco Freitas
}

\section{RESUMO}

Este artigo tem por objetivo propor a utilização pedagógica dos roteiros histórico-culturais no Centro Histórico da cidade de Porto Alegre/RS, através da sistematização de um projeto que contemple a teoria e a prática. Para tanto, a pesquisa pretende analisar as temáticas relacionadas à Educação Patrimonial, bem como a sua possível utilização como método de ensino de história para a educação básica. Através da proposta de pesquisa e investigação crítica que será colocada aos educandos pretendemos aplicar as concepções freireanas acerca de criticidade, diálogo e comunhão em espaços de educação não-formais.

PALAVRAS-CHAVE: Ensino de História. Educação Patrimonial. Roteiro histórico-cultural. Paulo Freire.

\begin{abstract}
This article aims to propose the use of pedagogical historical and cultural itineraries in the Historic Centre of Porto Alegre / RS, through the systematization of a project that includes theory and practice. Therefore, the research aims to examine the issues related to heritage education, as well as its possible use as a method of teaching history to basic education. Through the proposed research and critical research that will be put to the students plan to apply the Freire's concepts about criticality, dialogue and communion in spaces of non-formal education.
\end{abstract}

KEYWORDS: Teaching of History. Heritage Education. Paulo Freire.

\section{Introdução}

Durante muito tempo o ensino de história esteve atrelado a uma dinâmica simples e, supostamente, infalível: o professor repassava uma lista de datas e acontecimentos com a finalidade de que os seus alunos a memorizassem e fossem então capazes de reproduzi-la em provas escritas ou orais. 
Felizmente, educadores como Paulo Freire dedicaram a vida a combater esta concepção "bancária" da educação e importantes mudanças, sobretudo nos últimos anos, puderam se fazer sentir. Da mesma forma, com as interpretações da história surgidas com a Escola dos Annales, alterações positivamente significativas puderam ser implementadas na formação dos educadores.

Hoje buscamos contextualizar a história para os educandos, fazendo com que ela seja pertinente e que eles possam, juntamente com o educador, em sala de aula ou em espaços nãoformais de educação, refletir criticamente sobre mudanças e permanências históricas. É importante, neste sentido, que o educando seja também investigador e que ele seja estimulado a pesquisar e compartilhar os resultados de sua pesquisa.

No caso específico do trabalho que estamos desenvolvendo na Escola Estadual de Ensino Médio Agrônomo Pedro Pereira, em Porto Alegre, utilizaremos como ferramenta principal para a relação ensino/aprendizagem a atividade de roteiro histórico-cultural que é, precisamente, uma atividade que permitirá a atuação do educando como pesquisador.

Este projeto conta com o apoio e financiamento da Coordenação de Aperfeiçoamento de Pessoal de Nível Superior (CAPES) através do Programa Institucional de Bolsa de Iniciação à Docência (PIBID) do curso de História da Pontifícia Universidade Católica do Rio Grande do Sul (PUCRS).

O projeto, intitulado "O Tempo e o Centro", consiste em caminhadas pelo Centro Histórico de Porto Alegre, onde os alunos da educação básica são convidados a mergulharem no passado edificado da cidade, a fim de que eles possam tomar contato com o patrimônio histórico edificado, investigar criticamente este patrimônio, assim como a história de seu tombamento e preservação, e, sobretudo, aprender a valorizá-lo e preservá-lo, através de sua apropriação e interpretação, despertando o sentimento de pertença e compreendendo, enfim, que este patrimônio é de todos e por todos deve ser cuidado ${ }^{2}$.

\section{Educação Patrimonial}

\footnotetext{
${ }^{1}$ Ao criticar esta concepção Freire diz: “Em lugar de comunicar-se, o educador faz 'comunicados' e depósitos que os educandos, meras incidências, recebem pacientemente, memorizam e repetem. Eis aí a concepção 'bancária' da educação em que a única margem de ação que se oferece aos educandos é a de receberem os depósitos, guardá-los e arquivá-los”. (FREIRE, 2005, p. 66)

${ }^{2}$ Sobre estes aspectos é muito importante levarmos em consideração que "para reconhecer (conhecer de novo) o passado como um patrimônio temos que nos identificar com ele. No caso brasileiro, este processo é extremamente doloroso, já que a nossa sociedade sempre esteve, ainda está, alicerçada em fragmentos culturais, e a relação entre eles é de dominação". (GARBINATTO, 2000, p. 43)
} 
A educação para o patrimônio, ou educação patrimonial, é definida pelo Instituto do Patrimônio Histórico e Artístico Nacional (IPHAN) da seguinte forma:

\begin{abstract}
Um processo permanente e sistemático de trabalho educacional centrado no Patrimônio Cultural como fonte primária de conhecimento e enriquecimento individual e coletivo. Busca levar as crianças e adultos a um processo ativo de conhecimento, apropriação e valorização de sua herança cultural, capacitando-os para um melhor usufruto destes bens, e propiciando a geração e a produção de novos conhecimentos, num processo contínuo de criação cultural. (GUIA BÁSICO DE EDUCAÇÃO PATRIMONIAL, 1999, p. 7)
\end{abstract}

De acordo com este método, a educação patrimonial deve levar em consideração que somos seres históricos, portanto inseridos em uma sociedade que se constitui através de processos de longa duração e que somos herdeiros de um legado que deve ser usufruído, através do conhecimento e da apropriação. O IPHAN também destaca que a educação patrimonial serve como "recurso para a compreensão sócio-histórica das referências culturais em todas as suas manifestações, com o objetivo de colaborar para o seu reconhecimento, valorização e preservação". (EDUCAÇÃO PATRIMONIAL - MAIS EDUCAÇÃO, 2011).

Consideramos que um dos fatores mais importantes e que justifica a utilização da educação patrimonial nos currículos escolares é justamente a

falta de esclarecimento popular sobre a importância da preservação de nosso patrimônio, para não dizermos deseducação coletiva. Esse é um dado brasileiro e daí a formulação de mais uma regra: a preservação aqui entre nós depende fundamentalmente da elucidação popular, um caminho já percorrido por outros países, como o México, que dedica atenção toda especial a essa questão da educação de massa no que diz respeito à memória. (LEMOS, 1971, p. 84)

De acordo com Oriá (Oriá, 2001, p. 142), tendo por base a Lei 9.394/96³ , art. 26, é aberto o "espaço para a construção de uma proposta de ensino de História Local, voltada para a divulgação do acervo cultural dos municípios e estados". Neste sentido é que devemos encarar o uso, como item da educação patrimonial, da atividade de roteiro histórico, a fim de trabalharmos as questões referentes ao patrimônio histórico edificado da cidade com os alunos.

\title{
A conscientização através da educação patrimonial
}

\footnotetext{
${ }^{3}$ Disponível em <http://www.planalto.gov.br/ccivil_03/leis/L9394.htm> Acesso em 07/02/2013.
} 
Entendemos que é necessário o trabalho de educação patrimonial para que os jovens sejam, conscientemente, elementos protetores e propagadores do patrimônio histórico e cultural de suas cidades.

Para que não sejam ingênuos e compreendam o real valor daquilo que foi preservado do passado e que recria este passado no presente, de forma que se atribua a importância devida a este patrimônio a fim de evitar sua destruição em nome do "progresso" ou do “desenvolvimento". É aqui é fundamenta lembrarmos as palavras de Paulo Freire em relação à educação que não promove o senso crítico e a quem ela serve: “[...] anula o poder dos educandos ou o minimiza, estimulando sua ingenuidade e não sua criticidade, satisfaz aos interesses dos opressores [...]”. (FREIRE, 2005, p. 69)

Para que eles se apropriem do patrimônio que, a final de contas, é de toda a comunidade.

Para que eles percebam que são agentes ativos neste processo e que não fiquem passivamente aguardando que alguém ou algum órgão tome por si a iniciativa de preservação deste patrimônio que é de todos, combatendo assim aquilo que Paiva $(2008$, p. 7) chama de “ideia de que o individual deve ser cuidado pelo indivíduo; o que é coletivo fica a cargo de um ente sisudo, incompetente e desacreditado: um tal Estado".

A necessidade de estabelecer o protagonismo do próprio cidadão em relação à preservação do patrimônio histórico é premente. Exatamente aí está a importância do fomento à educação patrimonial, para que as escolas, sobretudo em suas aulas de história, invistam cada vez mais na utilização dos roteiros históricos culturais, levando os alunos para os lugares de memória e que estes funcionem como espaços educativos, de acordo com a seguinte definição:

Todo espaço que possibilite e estimule, positivamente, o desenvolvimento e as experiências do viver, do conviver, do pensar e do agir consequente [...] Portanto, qualquer espaço pode se tornar um espaço educativo, desde que um grupo de pessoas dele se aproprie, dando-lhe este caráter positivo, tirando-lhe o caráter negativo da passividade e transformando-o num instrumento ativo e dinâmico da ação de seus participantes, mesmo que seja para usá-lo como exemplo crítico de uma realidade que deveria ser outra [...] $\mathrm{O}$ arranjo destes espaços não deve se limitar a especialistas (arquitetos, engenheiros...), mas, sim, deve ser prática cotidiana de toda comunidade escolar. (EDUCAÇÃO PATRIMONIAL - MAIS EDUCAÇÃO, 2011)

É incalculável o valor que uma atividade como essa tem para os alunos e para o próprio professor. Afinal, para os alunos, a experiência de estarem reunidos com os colegas e com os professores em torno de um patrimônio histórico da sua própria cidade, 
compreendendo as transformações e as permanências históricas da sociedade na qual vivem tende a ser inesquecível. Neste sentido, Paulo Freire (2005, p. 79) já nos ensinava que "os homens se educam em comunhão, mediatizados pelo mundo, mediatizados pelos objetos cognoscíveis".

\section{A aula preparatória}

Ao iniciar a aula, o pibidiano ${ }^{4}$ deve ter em mente os objetivos globais a serem atingidos com o projeto: a) promover o contato dos alunos com o patrimônio histórico material da cidade de Porto Alegre, de forma que ele se aproprie dele e o interprete; b) estimular a reflexão crítica a respeito da preservação dos monumentos e prédios históricos; c) despertar outro olhar sobre o patrimônio histórico material da cidade que transcenda o sensocomum; d) problematizar o ensino em espaços não-formais de educação.

Para que possamos atingir estes objetivos, utilizaremos as quatro etapas da metodologia da Educação Patrimonial, segundo Oliveira (2008, p. 99): “observação, registro, exploração e apropriação". Acrescentaremos a elas mais uma etapa, que julgamos necessária e que consiste em uma aula introdutória. Portanto, as cinco etapas serão as seguintes: a) Introdução: aula/oficina com objetivo de preparar os alunos para o roteiro históricocultural. b) Observação: de acordo com o autor serve para "identificação do objeto, a função e o significado deste". É etapa realizada durante a caminhada. c) Registro: para a "fixação do conhecimento" e "aprofundamento da observação". Etapa igualmente realizada durante a caminhada. d) Exploração: é o momento onde se fará a "análise do problema" assim como "levantamento de hipóteses" e "discussão, questionamento". Esta etapa inicia durante a caminhada e prossegue no encontro posterior. e) Apropriação: é o momento onde os alunos produzirão um texto sobre a experiência, assim como poderão confeccionar cartazes contendo as fotografias que realizaram durante a caminhada, com o objetivo de "envolvimento afetivo, internalização, desenvolvimento da capacidade de auto-expressão, apropriação, participação criativa, valorização do bem cultural"

A partir destes eixos norteadores, o pibidiano encarregado de iniciar a aula deve fazer uma pequena abordagem que leve em consideração os conhecimentos prévios dos alunos promovendo o "diálogo com o educando, que ao ser educado, também educa" (FREIRE, 2005, p. 79) e assim trabalhar com a definição de conceitos-chave para a atividade. Portanto,

\footnotetext{
${ }^{4}$ Pibidiano é como os bolsistas PIBID se auto-intitulam.
} 
recomendamos que o pibidiano inicie sua fala questionando os alunos sobre o significado da palavra "patrimônio". Neste sentido, devemos lembrar que:

[...] o trabalho do professor se define como de mediador entre o aluno e o conhecimento histórico. Ele não só promove o diálogo com o conhecimento já sistematizado oficialmente, mas também com as memórias, com as vivências dos alunos. Essa é a matéria-prima da história ensinada e é disso que o professor/historiador edifica o seu trabalho. (HORN \& GERMINARI, 2006, p. 106)

Estabelecendo-se o significado de "patrimônio" devemos então passar ao próximo conceito. Perguntaremos aos alunos o que eles entendem por "patrimônio cultural". Usaremos como referência, porém de forma adaptada, com o objetivo de atingir maior didatismo, a definição de Lemos (1981, p. 8-10) e delimitaremos o conceito de Patrimônio Cultural em três partes distintas: 1) Os elementos da natureza: o meio ambiente de uma determinada sociedade. Por exemplo, para Porto Alegre o lago Guaíba ao qual a cidade se ergueu às margens e por este fato teve influência nos rumos que a cidade tomou; 2) Os saberes e os fazeres: no caso da cidade de Porto Alegre podemos usar como exemplos saber assar um bom churrasco ou então preparar um chimarrão etc.; 3) Os bens culturais que são fruto do meio ambiente e do saber fazer desta sociedade: jornais, edifícios, praças, cidades, ciências etc.

Neste ponto da aula os pibidianos devem entregar o material de trabalho aos alunos, que será utilizado em todas as aulas e na saída de campo. O material consiste em uma pasta de papel com o nome do projeto, da atividade, da escola e a identificação PIBID/História PUCRS. Na pasta constarão os seguintes itens: a) texto sobre arquitetura e memória; b) mapa; c) fichas de pesquisa; d) questionário de sondagem; e) questões para pesquisa.

Em seguida pediremos para que eles marquem no questionário quais os locais do roteiro que irão visitar e que já conhecem. Mostraremos então imagens dos locais e veremos se eles serão capazes de associar as imagens aos nomes dos locais ou vice-versa. Então indicaremos cada local a ser visitado no mapa e eles preencherão corretamente no mapa que receberam. A seguir, atribuiremos a cada um dos grupos a responsabilidade de pesquisar um dos prédios históricos a serem visitados com a incumbência de apresentarem esta pequena pesquisa no dia da caminhada no próprio monumento ou prédio escolhido pelo grupo. As perguntas que constarão como guia para a pesquisa poderão ser as seguintes: Qual o nome do monumento/prédio? Quando ele foi construído? Qual o motivo dele ter sido construído? Quando ele foi tombado como patrimônio histórico? Comente outras informações que você descobriu a respeito deste monumento/prédio. 
O objetivo desta etapa da atividade é dar autonomia para os alunos buscarem o conhecimento e propiciar seu momento de protagonismo na visita ao patrimônio histórico da cidade. Incentivar a pesquisa desde a educação básica é fundamental para a formação de cidadãos críticos e autônomos. Teremos então não somente alunos acostumados a serem receptores passivos daquilo que foi decidido pelo professor a ser transmitido, mas “investigadores críticos, em diálogo com o educador, investigador crítico também”.(FREIRE, 2005, p. 80). Podemos incluir material de pesquisa no site criado pelo PIBID/História PUCRS e orientar os educandos a buscarem algumas informações acessando-o.

Por fim, é feita a leitura em voz alta do texto do autor destacando-se as informações mais importantes e relacionando-as aos prédios que serão visitados ${ }^{5}$. Os alunos devem ser convidados a refletirem a respeito do texto e responderem uma questão que poderá variar de acordo com o monumento ou prédio histórico.

\title{
O Roteiro Histórico e Cultural
}

Caminhar para conhecer a história. Talvez seja este o grande sentido da atividade de roteiro histórico-cultural. É a oportunidade de proporcionar a experiência de caminhada histórica para que os educandos construam, passo a passo, suas próprias significações, interpretando e apropriando-se do patrimônio histórico da cidade a partir de suas ruas. De acordo com as palavras de Michel de Certeau:

\begin{abstract}
A história começa no nível do chão, com passos. São miríades, mas não compõem uma série. Não se pode contá-los porque cada unidade tem um caráter qualitativo: um estilo de apreensão táctil e apropriação quinestética. Sua massa fervilhante é uma coleção inumerável de singularidades. Suas trilhas entrelaçadas dão sua forma aos espaços. Eles tecem lugares em conjunto. A esse respeito, os movimentos pedestres formam um desses "sistemas reais cuja existência de fato constrói a cidade". Não os localizamos, ou melhor, são eles que se espacializam. (CERTEAU, 1994, p. 28)
\end{abstract}

Aprender com os movimentos do próprio corpo, com os passos que conduzem a observação e a partir desta a reflexão. A história não é somente construída nas ruas das cidades, mas também pode e deve ser ensinada a partir destas mesmas ruas.

\footnotetext{
${ }^{5}$ Por exemplo, podemos salientar o seguinte trecho: "O gênero humano enfim não tem pensado nada importante que não o tenha escrito em pedra. E por quê? Porque todo o pensamento, quer religioso, quer filosófico, tem interesse em se perpetuar. A ideia que agitou uma geração quer agitar outras e deixar vestígios". (HUGO, 1945 , p. 227). A partir dele podemos colocar questões no seguinte sentido: Qual monumento em Porto Alegre que você conhece que perpetuou uma idéia?, ou então: Você acha que podemos conhecer melhor o passado através dos monumentos históricos?
} 
É com este espírito que realizaremos a caminhada pelo Centro Histórico de Porto Alegre. O trecho selecionado contempla o Palácio Piratini, a Catedral Metropolitana, a Praça da Matriz, o Theatro São Pedro, o Paço Municipal, Mercado Público e Chalé da Praça XV. Em cada um dos locais os pibidianos devem estar preparados para expor e apontar detalhes ou características, de forma articulada com a história da cidade. Da mesma forma será neste momento que cada grupo de alunos da educação básica poderá apresentar, no próprio espaço visitado, o resultado de sua pesquisa a respeito daquele prédio ou local histórico.

\section{O encontro após o Roteiro Histórico-Cultural}

Com o término da caminhada, solicitaremos aos alunos que escrevam em casa um pequeno relato sobre a atividade e sobre os locais visitados. Para isto, eles deverão utilizar as anotações que realizaram nas fichas e também deverão expressar suas impressões a respeito do patrimônio histórico visitado. Com isto, estaremos finalizando o processo de apropriação do patrimônio histórico por parte dos alunos. Eles poderão refletir a respeito e indicar, através do texto, a relação que tinham antes e a relação que passaram a ter após a atividade com o patrimônio histórico local. Da mesma forma, os alunos devem ser instruídos a levarem na próxima aula os cartões de memória ou pendrives com as fotografias que realizaram durante a atividade, pois estas serão o material com o qual construiremos um cartaz (ou cartazes) para uma exposição na escola onde será relatada a caminhada histórica pelo centro de Porto Alegre. Desta maneira, os alunos serão estimulados a comunicarem para a comunidade escolar os resultados da sua saída de campo. Portanto, nesta aula posterior ao roteiro histórico-cultural, faremos um debate em torno das redações feitas pelos alunos, das fotografias que realizaram e das impressões que eles ficaram a respeito dos locais visitados e de suas respectivas histórias.

\section{Conclusão}

Após estes três encontros entre pibidianos e alunos da educação básica, onde além de trabalhar teoricamente, trabalhamos empiricamente as noções acerca do patrimônio históricocultural, saímos com a certeza de que os educandos puderam ganhar, além do contato com o patrimônio histórico da sua cidade, maior autonomia em relação ao estudo da história.

Conhecer, pesquisar, visitar e apropriar-se são os verbos fundamentais para esta atividade. O educando em um primeiro momento é apresentado de forma teórica ao 
patrimônio de sua cidade e é convidado em seguida a pesquisá-lo a fim de qualificar ainda mais este primeiro contato. Após, é realizada a saída de campo, onde o educando, em contato direto com a fonte histórica edificada, poderá falar a respeito dela com base na pesquisa realizada anteriormente. Para finalizar a atividade, é produzida uma redação e um cartaz com as fotografias realizadas. Desta forma, através da interpretação reflexiva da escrita, estaremos garantindo a apropriação, por parte dos alunos, do patrimônio histórico de sua cidade.

Enfim, este processo, dividido em três partes, possibilitará a autonomia para o educando buscar o conhecimento por meio de pesquisa. Serão trabalhadas questões importantes para o desenvolvimento do senso crítico, favoráveis ao diálogo, tanto entre educandos e educadores, quanto ao diálogo do educando com o objeto de pesquisa. Afinal, como já ensinava Paulo Freire "ensinar não é transferir conhecimento, mas criar as possibilidades para a sua produção ou a sua construção". (FREIRE, 1996, p. 22).

\section{Referências}

CERTEAU, Michel de. Andando na cidade. Revista do Patrimônio Histórico e Artístico Nacional, n. 23, p. 21-31, Org. Heloisa Buarque de Holanda. Ministério da Cultura, 1994.

FREIRE, Paulo. Pedagogia da autonomia: saberes necessários à prática educativa. São Paulo: Paz e Terra, 1996.

FREIRE, Paulo. Pedagogia do oprimido. Rio de Janeiro: Paz e Terra, 2005.

GARBINATTO, Valeska. Ensino de história e patrimônio histórico: pontes para a construção da memória e cidadania. Ciências \& Letras, Porto Alegre, n. 27, p. 37-48, jan./jun. 2000 .

Guia Básico de Educação Patrimonial. Maria de Lourdes Parreira Horta. Evelina Grunberg e Adriane Queiroz Monteiro. Brasília, Museu Imperial/IPHAN/MinC, 1999.

HORN, Geraldo Balduíno. GERMINARI, Geyso Dongley. O ensino da história e seu currículo: teoria e método. Petrópolis, RJ: Vozes, 2006.

HUGO, Vítor. Nossa Senhora de Paris. Porto: Livraria Chardron, 1945.

KROHN, Ellen Christina Ribeiro et. al. EDUCAÇÃO PATRIMONIAL - PROGRAMA MAIS EDUCAÇÃOO. Parceria IPHAN/MEC, 2011. Disponível em $<$ http://portal.mec.gov.br/index.php?option=com_docman\&task=doc_download\&gid=10290 \&Itemid=> Acesso em 13 fev. 2013.

LEMOS, Carlos A. C. O que é Patrimônio Histórico? São Paulo: Brasiliense, 1981. 
OLIVEIRA, Almir Félix Batista de. Patrimônio, memória e ensino de história. In OLIVEIRA, Margarida Dias de (org.). Ensino de história: múltiplos ensinos em múltiplos espaços. Natal: EDFURN, 2008.

ORIÁ, Ricardo. Memória e ensino de história. In BITTENCOURT, Circe (org.) O saber histórico na sala de aula. São Paulo: Contexto, 2004.

PAIVA, Salma Saadi Waress de. Prefácio. In BARRETO, Euder Arrais et. al. Patrimônio cultural e educação: artigos e resultados. Goiânia: Universidade Federal de Goiás, 2008. 